\title{
The transrepression arm of glucocorticoid receptor signaling is protective in mutant huntingtin-mediated neurodegeneration
}

\author{
S Varadarajan ${ }^{1}$, C Breda ${ }^{2,5}$, JL Smalley ${ }^{3,5}$, M Butterworth ${ }^{3}$, SN Farrow ${ }^{4}$, F Giorgini' ${ }^{2}$ and GM Cohen ${ }^{\star, 1}$
}

The unfolded protein response (UPR) occurs following the accumulation of unfolded proteins in the endoplasmic reticulum (ER) and orchestrates an intricate balance between its prosurvival and apoptotic arms to restore cellular homeostasis and integrity. However, in certain neurodegenerative diseases, the apoptotic arm of the UPR is enhanced, resulting in excessive neuronal cell death and disease progression, both of which can be overcome by modulating the UPR. Here, we describe a novel crosstalk between glucocorticoid receptor signaling and the apoptotic arm of the UPR, thus highlighting the potential of glucocorticoid therapy in treating neurodegenerative diseases. Several glucocorticoids, but not mineralocorticoids, selectively antagonize ER stress-induced apoptosis in a manner that is downstream of and/or independent of the conventional UPR pathways. Using GRT10, a novel selective pharmacological modulator of glucocorticoid signaling, we describe the importance of the transrepression arm of the glucocorticoid signaling pathway in protection against ER stress-induced apoptosis. Furthermore, we also observe the protective effects of glucocorticoids in vivo in a Drosophila model of Huntington's disease (HD), wherein treatment with different glucocorticoids diminished rhabdomere loss and conferred neuroprotection. Finally, we find that growth differentiation factor 15 has an important role downstream of glucocorticoid signaling in antagonizing ER stress-induced apoptosis in cells, as well as in preventing HD-mediated neurodegeneration in flies. Thus, our studies demonstrate that this novel crosstalk has the potential to be effectively exploited in alleviating several neurodegenerative disorders.

Cell Death and Differentiation (2015) 22, 1388-1396; doi:10.1038/cdd.2015.1; published online 6 February 2015

The unfolded protein response (UPR) occurs in response to the accumulation of unfolded and misfolded proteins in the endoplasmic reticulum (ER) and executes a coordinated sequence of intracellular events, all of which are designed to restore cellular homeostasis in the stressed cells. ${ }^{1-3}$ This is achieved by the activation of the three major arms of the UPR, involving inositol-requiring protein-1 a (IRE1a), activating transcription factor-6 (ATF6) and protein kinase RNA-like ER kinase (PERK), which in turn mediate a series of events, including the phosphorylation of an eukaryotic translation initiation factor $2 a$ (elF2a) to temporarily arrest protein synthesis, and generation of chaperones such as binding immunoglobulin protein (BiP) to aid in protein folding. ${ }^{1-3}$ However, when the extent of stress is overwhelming, the UPR activates the apoptotic arm, which includes the accumulation of $\mathrm{C} / \mathrm{EBP}$ homologous protein $(\mathrm{CHOP})$, resulting in the clearance of stressed cells. ${ }^{4,5}$ As canonical ER stress and the UPR have been implicated in a number of disorders, including diabetes, cancer and several neurodegenerative diseases, efforts have been made to modulate specific arms of the UPR in an attempt to minimize disease pathology and improve survival. $^{6-9}$ This has led to the design of compounds that specifically inhibit different arms of the ER stress pathway, such as inhibitors of PERK and elF2 $a$ dephosphorylation (salubrinal and guanabenz), IRE1a (STF-083010 and MKC-3946) and ATF6 proteolysis (AEBSF), all of which efficiently modulate specific arms of the ER stress pathway to achieve therapeutic benefits. ${ }^{10-14}$

Glucocorticoids exert pleomorphic effects on a variety of physiological responses and are widely prescribed to treat several inflammatory diseases, including asthma, rheumatoid arthritis and allergic rhinitis. ${ }^{15}$ Owing to their propensity to induce apoptosis, high-dose glucocorticoids are also an integral part of chemotherapy regimens in the treatment of several leukemias and lymphomas. ${ }^{16,17}$ However, recent reports also claim specific prosurvival roles of glucocorticoids. ${ }^{18-21}$ Glucocorticoid signaling involves the nuclear translocation of the dimerized ligand-receptor complex, which in turn results in the induction of several antiinflammatory proteins as well as regulatory proteins important for metabolism. This pathway, also known as transactivation, is believed to be responsible for many of the side effects of glucocorticoids. ${ }^{22}$ Alternatively, the transrepression arm of glucocorticoid signaling involves the direct or indirect interaction of the monomeric receptor complex with specific transcription factors to regulate negatively proinflammatory

\footnotetext{
${ }^{1}$ Department of Molecular and Clinical Cancer Medicine and Pharmacology, University of Liverpool, Liverpool, UK; '2Department of Genetics, University of Leicester, Leicester, UK; ${ }^{3} \mathrm{MRC}$ Toxicology Unit, University of Leicester, Leicester, UK and ${ }^{4}$ Respiratory Therapy Area, GlaxoSmithKline, Stevenage, UK

*Corresponding author: GM Cohen, Department of Molecular and Clinical Cancer Medicine, University of Liverpool, The Duncan Building, Daulby Street, Liverpool L69 $3 G A$, UK. Tel: +44 151 7064515; Fax: +44 151 7065826; E-mail: gmc2@liv.ac.uk

${ }^{5}$ These authors contributed equally to this work.

Abbreviations: ATF6, activating transcription factor-6; BiP, binding immunoglobulin protein; BFA, brefeldin A; CHOP, C/EBP homologous protein; DTT, dithiothreitol; elF2 $\alpha$, eukaryotic translation initiation factor $2 \alpha$; ER, endoplasmic reticulum; GDF15, growth differentiation factor 15; HD, Huntington's disease; HTT, huntingtin; IRE1 $\alpha$, inositol-requiring protein-1 $\alpha$; PERK, protein kinase RNA-like ER kinase; THG, thapsigargin; UPR, unfolded protein response

Received 04.6.14; revised 15.12.14; accepted 07.1.15; Edited by RA Knight; published online 06.2.15
} 
gene expression, finally resulting in anti-inflammatory and immunosuppressive effects. ${ }^{22}$ In an attempt to improve the therapeutic index of these compounds, structural variants of glucocorticoids that selectively modulate the transrepression arm of glucocorticoid signaling are currently being developed. ${ }^{23-31}$

In the present study, we describe a novel crosstalk between glucocorticoid signaling and the apoptotic arm of the UPR, highlighting the potential use of glucocorticoid therapy in several disease conditions. Using a selective modulator of glucocorticoid signaling, GRT10, we further establish a role for the transrepression arm of glucocorticoid signaling in the inhibition of ER stress-induced apoptosis. Furthermore, using microarray analysis, we identify growth differentiation factor 15 (GDF15) as a major player in ER stress-induced apoptosis that can be effectively downregulated by the transrepression arm of glucocorticoid signaling. Finally, as ER stress has a central role in several neurodegenerative diseases, we exploit a fruit fly model of Huntington's disease (HD), which expresses a fragment of mutant huntingtin (HTT) - the causative protein in this disorder - to validate the therapeutic potential of glucocorticoid signaling and GDF15 in HD, and find that this novel crosstalk could be an important target for designing drugs to alleviate several neurodegenerative diseases.

\section{Results}

Mometasone furoate antagonizes ER stress-induced apoptosis with little changes to the major arms of the UPR. Following a series of screening experiments, we found that treatment with mometasone furoate, a glucocorticoid commonly used to treat inflammation of the skin and airways, resulted in significant protection against apoptosis induced by several conventional ER stressors, including tunicamycin, brefeldin A (BFA), thapsigargin (THG) and dithiothreitol (DTT) (Figure 1a). This protective effect was comparable with that of the $a-2$ adrenergic receptor agonist (guanabenz). ${ }^{11}$ Both mometasone and guanabenz also protected against tunicamycin-induced activation of caspase- $9,-7$ and -3 , as well as cleavage of the canonical caspase substrate (poly (ADP-ribose) polymerase (PARP)) (Figure 1b). The protective effect of guanabenz against ER stress-induced apoptosis has been attributed to its ability to sustain the phosphorylation

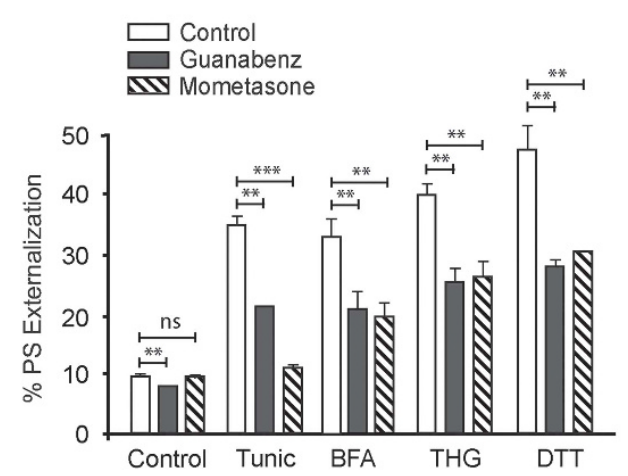

d

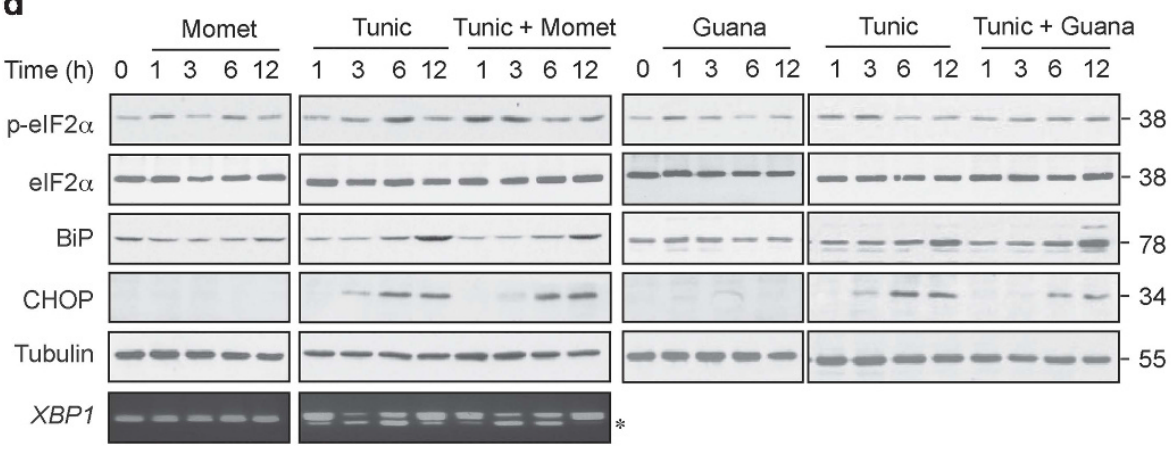

b

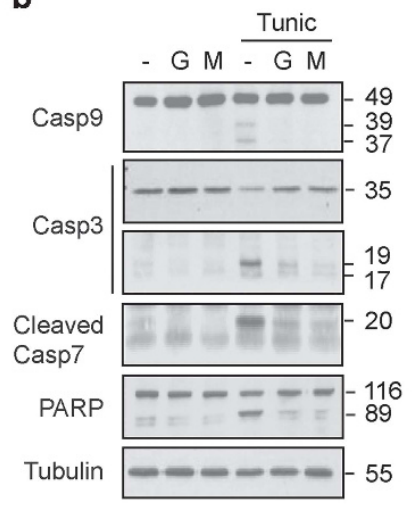

c

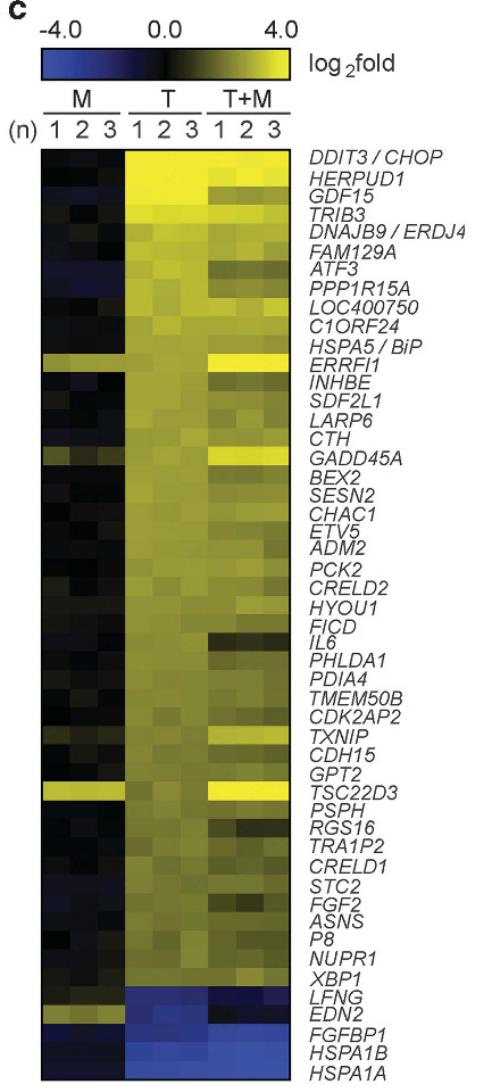

Figure 1 Mometasone protects against ER stress-induced apoptosis with few changes to the UPR. (a) HeLa cells exposed for $4 \mathrm{~h}$ to dimethyl sulfoxide (DMSO), mometasone or guanabenz $(1 \mu \mathrm{M})$, followed by $20 \mathrm{~h}$ of tunicamycin (Tunic; $10 \mu \mathrm{M})$, BFA $(10 \mu \mathrm{M})$, THG $(10 \mu \mathrm{M})$ or DTT (1 mM), were analyzed by fluorescence-activated cell sorting (FACS) for PS externalization $(n=3)$. Statistical analysis was conducted by paired $t$-test $\left({ }^{\star * *} P<0.001,{ }^{* \star} P<0.01\right.$, NS, not significant, if $\left.P>0.05\right)$. (b) HeLa cells exposed to DMSO, mometasone or guanabenz $(1 \mu \mathrm{M})$ for $4 \mathrm{~h}$, followed by $20 \mathrm{~h}$ of tunicamycin, were immunoblotted with the indicated antibodies to detect apoptosis. (c) Heatmap analysis comparing gene changes in HeLa cells following $4 \mathrm{~h}$ of DMSO or mometasone $(\mathrm{M} ; 1 \mu \mathrm{M})$, followed by a further $20 \mathrm{~h}$ of tunicamycin $(\mathrm{T}$; $10 \mu \mathrm{M})$, where yellow and blue indicate upor downregulation of genes, respectively. The results are shown for three independent experiments $(n=1-3)$. (d) Total RNA or whole-cell lysates of HeLa cells exposed to either mometasone $(1 \mu \mathrm{M})$ or guanabenz $(1 \mu \mathrm{M})$ alone or in combination with tunicamycin $(10 \mu \mathrm{M})$ for the indicated times were either processed for reverse transcription-PCR (RT-PCR) to identify spliced fragment of $x b p 1$ or immunoblotted with the indicated antibodies to detect changes in the major arms of the UPR 
status of elF2 $a$, which in turn resulted in a temporary block of global translation and modulation of the major arms of the UPR. ${ }^{11}$ As mometasone was equally efficacious in antagonizing ER stress-induced apoptosis, we speculated that the protective effects of mometasone, similar to guanabenz, could be due to changes in phospho-elF2 $a$ levels and other arms of the UPR. However, mometasone failed to alter most UPR-mediated RNA and protein changes (Figures 1c and d), despite fluctuating levels of the phosphorylated form of elF2a (Figure 1d). In contrast, guanabenz mediated sustained levels of phospho-elF2 $a$ and inhibited CHOP accumulation (Figure 1d), thereby suggesting that the protective effects of mometasone could be distinct from those of guanabenz.

Glucocorticoid receptor signaling is critical for the antiapoptotic functions of glucocorticoids. The protective effect of mometasone was more restricted to cell death induced by canonical ER stressors than other cell death stimuli, as the extent of rescue from apoptosis in cells exposed to common cell death stimuli, such as the kinase inhibitor (staurosporine), the BCL-2 inhibitor (ABT-263), the proteasomal inhibitor (MG132), the translation inhibitor (cycloheximide) or an oxidizing agent (hydrogen peroxide $\left(\mathrm{H}_{2} \mathrm{O}_{2}\right)$ ), was not statistically significant (Figure 2a), The protective effects of mometasone gradually diminished over time, suggesting that repeated administration of mometasone may be required to prolong the protective response (Figure 2b). In most of these experiments, mometasone was added to the cells at least $4 \mathrm{~h}$ before tunicamycin treatment, to ensure complete activation of the glucocorticoid receptor signaling pathways. However, altering the exposure times to mometasone yielded similar protection against tunicamycin-induced apoptosis (Figure 2c), thus suggesting that preconditioning of cells is not a requirement for efficient inhibition of the apoptotic arm of the UPR. Furthermore, the ability to antagonize ER stress-induced apoptosis was not restricted to mometasone, as several glucocorticoids, but not mineralocorticoids, also diminished tunicamycin-mediated apoptosis (Figure 2d). To attribute these protective effects of glucocorticoids to elevated glucocorticoid receptor signaling, we used a competitive inhibitor (mifepristone), ${ }^{32}$ which completely reversed the antiapoptotic effects of budesonide
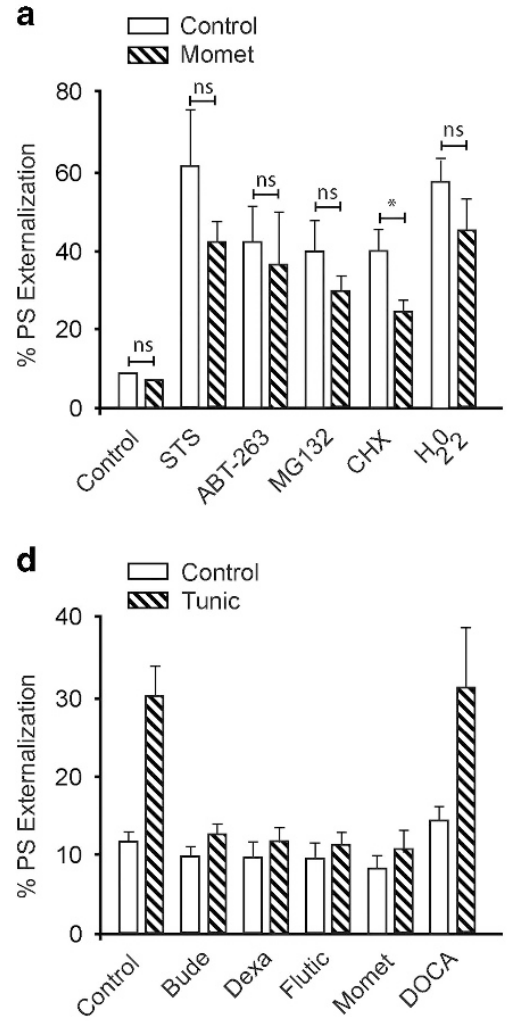

b

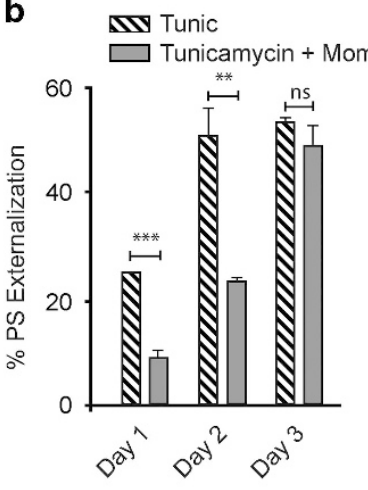

e

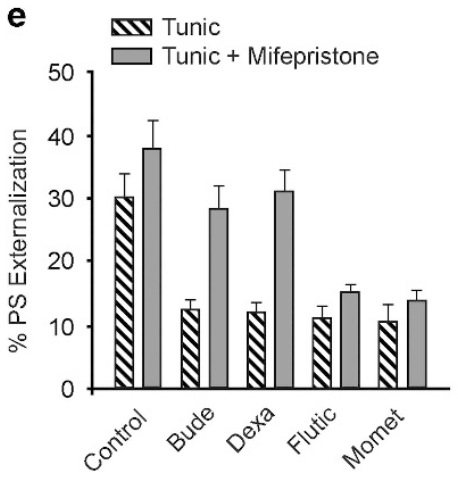

C

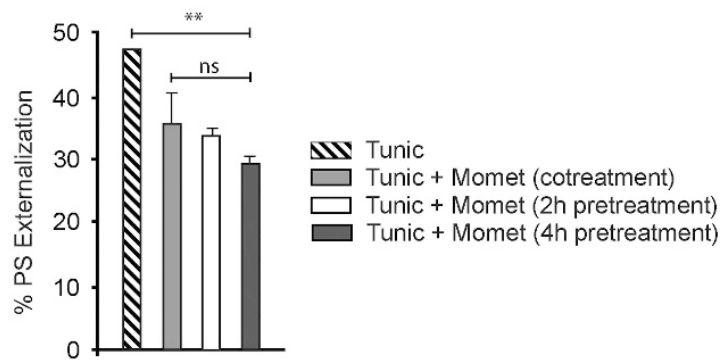

Figure 2 Glucocorticoid receptor signaling is critical for the protective effects of the glucocorticoids. (a) HeLa cells exposed for $4 \mathrm{~h}$ to $1 \mu \mathrm{M}$ of mometasone, followed by $20 \mathrm{~h}$ of staurosporine (STS; $1 \mu \mathrm{M})$, ABT-263 $(10 \mu \mathrm{M})$, MG132 $(20 \mu \mathrm{M})$, cycloheximide $(\mathrm{CHX} ; 20 \mu \mathrm{M})$ or hydrogen peroxide $\left(\mathrm{H}_{2} \mathrm{O}_{2} ; 100 \mu \mathrm{M}\right)$, were analyzed by FACS for PS externalization ( $n=3)$. Statistical analysis was conducted by paired $t$-test $\left({ }^{*} P<0.05\right.$, NS, not significant, if $\left.P>0.05\right)$. (b) HeLa cells exposed for $4 \mathrm{~h}$ to mometasone $(1 \mu \mathrm{M})$, followed by tunicamycin (Tunic; $10 \mu \mathrm{M}$ ) for 1-3 days, were analyzed by FACS for PS externalization $(n=3)$. Statistical analysis was conducted by paired $t$-test $(* \star \star P<0.001$, ${ }^{* *} P<0.01$, NS, not significant, if $\left.P>0.05\right)$. (c) HeLa cells exposed to mometasone $(1 \mu \mathrm{M})$ for $0,2 \mathrm{~h}$ or $4 \mathrm{~h}$, followed by tunicamycin (Tunic; $\left.10 \mu \mathrm{M}\right)$ for a further $20 \mathrm{~h}$, were analyzed by FACS for PS externalization $(n=3)$. Statistical analysis was conducted by paired $t$-test ${ }^{* *} P<0.01$, NS, not significant, if $\left.P>0.05\right)$. (d) HeLa cells exposed for $4 \mathrm{~h}$ to $1 \mu \mathrm{M}$ of budesonide (Bude), dexamethasone (Dexa), fluticasone propionate (Flutic), mometasone furoate (Momet) or deoxycorticosterone acetate (DOCA), followed by $20 \mathrm{~h}$ of tunicamycin $(10 \mu \mathrm{M})$, were analyzed by FACS for PS externalization $(n=3)$. (e) HeLa cells, pretreated for $0.5 \mathrm{~h}$ with mifepristone $(20 \mu \mathrm{M})$, were subjected to other treatments as specified in (d) and analyzed by FACS for PS externalization $(n=3)$. (f) HeLa cells, reverse transfected with $10 \mathrm{nM}$ of control or glucocorticoid receptor small interfering RNA (siRNA), were exposed to mometasone $(1 \mu \mathrm{M})$ for $4 \mathrm{~h}$, followed by $20 \mathrm{~h}$ of tunicamycin and assessed for apoptosis. Immunoblots confirmed the knockdown efficiency of the siRNA oligoduplexes $(n=3)$ 
and dexamethasone but not those of fluticasone and mometasone (Figure 2e). This was most likely due to the high association and low dissociation rate constants of fluticasone and mometasone with the glucocorticoid receptor. $^{33}$ Furthermore, silencing the cellular expression levels of the glucocorticoid receptor completely abolished the ability of mometasone to protect against tunicamycin-induced apoptosis (Figure 2f), thus confirming the existence of a crosstalk between glucocorticoid receptor signaling and ER stress-induced apoptosis.

The transrepression arm of glucocorticoid signaling antagonizes ER stress-induced apoptosis and ameliorates mutant HTT-mediated neurodegeneration. To determine the relative contributions of transactivation and transrepression pathways to the protective effects, we used a novel and selective modulator of glucocorticoid signaling (GRT10), which is unable to transactivate effectively glucocorticoid-dependent gene expression but demonstrates full transrepression activity (Figure $3 a$ ). ${ }^{29}$ Similar to mometasone, GRT10 exhibited antiapoptotic effects, even at nanomolar concentrations (Figure $3 \mathrm{~b}$ ), thus demonstrating that the transrepression arm of glucocorticoid signaling is sufficient to inhibit ER stress-induced apoptosis. As ER stress-induced apoptosis is linked to the incidence of several neurodegenerative diseases, we wished to assess whether glucocorticoids could ameliorate neurodegeneration in a relevant in vivo model. Therefore, we used a Drosophila model of $\mathrm{HD}$, in which flies pan-neuronally express a mutant HTT exon 1 fragment (HTT93Q) and exhibit a progressive loss of photoreceptor neurons (rhabdomeres) during their lifespan. ${ }^{34-38}$ Treatment of adult HD flies with either mometasone or GRT10 markedly rescued mutant HTT-mediated neurodegeneration, although the extent of protection with GRT10 was slightly lower than with mometasone (Figures 3c and $\mathrm{d}$ ). Moreover, treatment of the glucocorticoids during larval stages reduced neurodegeneration in newly emerged (day 0) HD flies (Figure 3e), suggesting that the transrepression arm of glucocorticoid signaling is neuroprotective both in adult HD flies and during development.

GDF15 has a critical role in regulating the antiapoptotic functions of glucocorticoids. To identify the target downstream of the transrepression arm that was critical for a

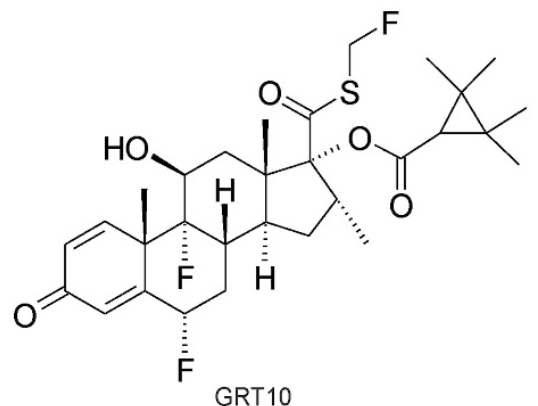

c

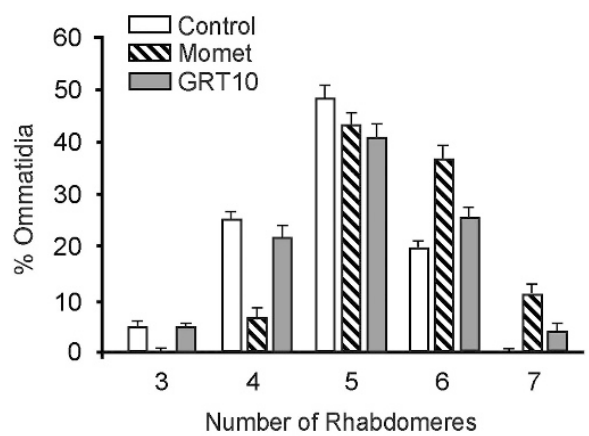

b

-x- GRT10+Tunicamycin

* Mometasone+Tunicamycin

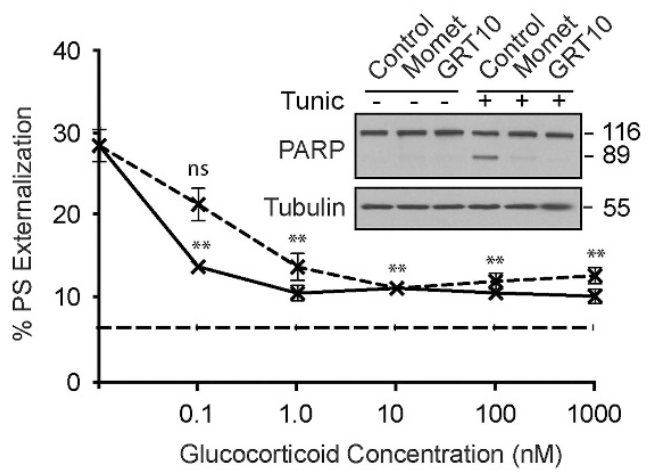

d

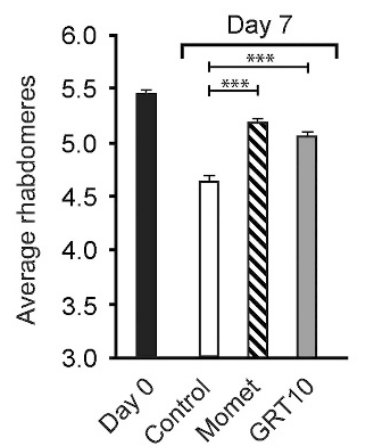

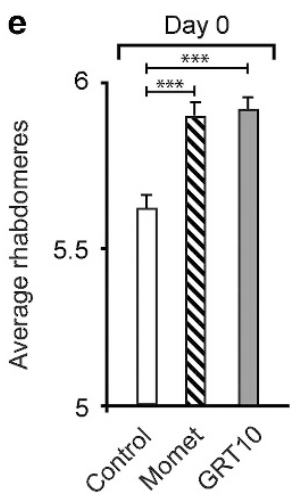

Figure 3 The transrepression arm of glucocorticoid signaling is sufficient to protect against ER stress-induced apoptosis and HTT-mediated neurodegeneration. (a) Chemical structure of GRT10. The transrepression and transactivation assays characterizing the specificity of GRT10 have previously been published, where GRT10 is denoted as compound $5{ }^{29}$ (b) HeLa cells, exposed for $4 \mathrm{~h}$ to the indicated concentrations of GRT10 and mometasone, followed by a further $20 \mathrm{~h}$ of tunicamycin (10 $\mu \mathrm{M}$ ), were analyzed by FACS for PS externalization $(n=3)$. Dashed, straight line at the bottom depicts the extent of basal cell death in control cells. Statistical analysis was conducted using a paired $t$-test ( ${ }^{\star *} P<0.01$, NS, not significant, if $\left.P>0.05\right)$. The inset shows the extent of apoptosis assessed by cleavage of PARP. (c) Newly emerged fruit flies, expressing mutant HTT, were exposed to either mometasone (10 $\mu \mathrm{M}, n=14)$ or GRT10 $(10 \mu \mathrm{M}, n=11)$ for 7 days and the number of rhabdomeres per ommatidium was scored by pseudopupil analysis. (d) Same as (c), but the average number of rhabdomeres per ommatidium has been plotted. Statistical analysis was conducted by analysis of variance (ANOVA) with NewmanKeuls post hoc tests $\left.{ }^{* * *} P<0.001\right)$. (e) Same as $($ d), but the analysis was carried out with day 0 flies to assess HTT-mediated neurodegeneration during development $(n=11-13)$. Statistical analysis was conducted by ANOVA with Newman-Keuls post hoc tests $\left({ }^{* \star *} P<0.001\right)$ 
neuroprotection, we performed microarray analysis following tunicamycin in the presence of mometasone or GRT10. While mometasone or GRT10 exhibited varied effects on tunicamycin-mediated transcriptional changes, only a limited subset of genes induced by tunicamycin was maximally decreased by both mometasone and GRT10 (Figure 4a). Of these genes, the induction of GDF15 following ER stress, which was efficiently diminished both at RNA and protein levels by mometasone and GRT10 (Figure 4b), was intriguing, as we observed a similar, time-dependent induction of GDF15 in immortalized rat adrenal gland phaeochromocytoma PC12 cells expressing a mutant HTT fragment (Figure 4c). ${ }^{39}$ To assess if GDF15 upregulation was responsible for ER stressinduced apoptosis, we used RNA interference to silence the expression of GDF15 in cells. Following silencing of GDF15, tunicamycin-induced apoptosis was significantly reduced (Figure 4d), thus confirming the involvement of GDF15 in ER stress-induced apoptosis. Furthermore, exposure of GRT10 to cells that lack GDF15 did not significantly enhance the protection (Figure 4d), thus suggesting that GDF15 was one of the major and crucial targets of GRT10, with respect to their antiapoptotic functions. These observations were further confirmed in vivo, wherein genetic inhibition of maverick (mav) - the Drosophila ortholog of GDF15 - by RNAi efficiently ameliorated HD-relevant photoreceptor loss at day 7 (Figure 4e). Interestingly, we observed a significant age $\times$ genotype interaction $\left(F_{(1,46)}=7.76, P<0.01\right)$, suggesting that knockdown of mav is not only neuroprotective but slows progression of neuron loss in this animal model (Figure 4e). Finally, in agreement with our findings in cells, further treatment of GRT10 on flies lacking mav failed to enhance the extent of protection from baseline (Figure 4f), confirming that mav is a critical target of the transrepression arm of glucocorticoid receptor signaling. Taken together, our data suggest that the transrepression arm of glucocorticoid signaling ameliorates mutant HTT-mediated neurodegeneration (Figure 5), and this novel crosstalk between GDF15 and the transrepression arm of glucocorticoid signaling could be an important target in the design of drugs to alleviate other neurodegenerative disorders in addition to $\mathrm{HD}$, including Alzheimer's and Parkinson's diseases.

\section{Discussion}

$\mathrm{HD}$ is a neurodegenerative disorder characterized by psychological problems, cognitive dysfunction, motor impairment and ultimately death. A prominent feature of HD pathology is the assembly of mutant HTT protein into cytoplasmic- and nuclearinsoluble amyloid-like fibrils, as well as soluble oligomeric species. ${ }^{40}$ Although the disease pathology has been attributed to a mutation in the HTT gene, resulting in the expansion of the polyglutamine tract in the HTT protein, $^{41}$ the molecular mechanisms underlying mutant $\mathrm{HTT}$ toxicity are poorly understood. However, a number of pathological mechanisms, including mitochondrial dysfunction ${ }^{42,43}$ and ER stress ${ }^{7,44}$ have been implicated in HD. Currently, there is no cure for HD, with drugs only available for symptomatic treatment. ${ }^{45}$

Canonical ER stress response and the UPR have been implicated in a wide variety of disorders, including diabetes, cancer, inflammatory diseases and neurodegeneration. ${ }^{6}$ Although an enhanced activation of the survival arms of the UPR is observed in cancers, the apoptotic pathways are more prevalent in several neurodegenerative diseases. ${ }^{6,9}$ UPR-targeted gene manipulation, such as the deletion of the proapoptotic protein $\mathrm{CHOP}$, has been observed to delay disease onset and improve survival in Parkinson's disease and amyotrophic lateral sclerosis. ${ }^{46,47}$ ER stress-induced apoptosis has been implicated as an important contributor to cellular toxicity in several models of HD. ${ }^{48-53}$ Furthermore, other UPR modulators (such as salubrinal, several chemical chaperones, overexpression of GRP78 and downregulation of SCAMP5, Rrs1 and ASK1) have been successfully used in alleviating HD-associated phenotypes. ${ }^{10,49,52,54-60}$ Recently, guanabenz, an $a-2$ adrenergic receptor agonist, was reported to exhibit significant protection against apoptosis via selective modulation of the UPR. ${ }^{11}$ Unlike guanabenz, which antagonizes ER stressinduced apoptosis by blocking most UPR pathways, glucocorticoids exert their protective effects downstream of and/or independent of the major arms of the UPR (Figures 1 and 2).

Although previous studies have reported protective roles for glucocorticoids in cell death, ${ }^{61-63}$ our current study characterizes a role for transrepression and not transactivation in the glucocorticoid-mediated protection against ER stress-induced apoptosis (Figure 3). Notably, we have identified, characterized and validated a role of GDF15 in ER stress-induced apoptosis (Figure 4). The ability of glucocorticoids to repress the transcription of GDF15, in a manner that is partly dependent on the Brm Swi/Snf ATPase, has been documented. ${ }^{64}$ Furthermore, downregulation of Brm increased glucocorticoid receptor occupancy most likely by competing with the glucocorticoids to bind the receptor, thus modulating GDF15 transrepression. ${ }^{64}$ This raises the possibility that inactivation of Brm ATPase may abrogate the protective effects of glucocorticoids against ER stress-

Figure 4 GDF15 regulates ER stress-induced apoptosis and HD-associated neurodegeneration. (a) Heatmap analysis comparing gene changes in HeLa cells, following $4 \mathrm{~h}$ of mometasone $(1 \mu \mathrm{M})$ or GRT10 $(0.1 \mu \mathrm{M})$, followed by a further $20 \mathrm{~h}$ of dimethyl sulfoxide (DMSO) or tunicamycin $(10 \mu \mathrm{M})$, where yellow and blue indicate up- or downregulation of genes, respectively. The results are shown for three independent experiments $(n=1-3)$. (b) Whole-cell lysates of HeLa cells exposed for $4 \mathrm{~h}$ to either mometasone $(1 \mu \mathrm{M})$ or GRT10 $(0.1 \mu \mathrm{M})$ alone or in combination with tunicamycin $(10 \mu \mathrm{M})$ for a further $20 \mathrm{~h}$ were immunoblotted with the indicated antibodies. (c) Heatmap analysis comparing gene changes in tunicamycin-treated HeLa cells $(10 \mu \mathrm{M}$ for $20 \mathrm{~h})$ to microarray data sets obtained in PC12-HTT103Q-GFP cells following the induction of HTT expression using a steroid inducer, ponasterone A $(5 \mu \mathrm{M})$ for the indicated times $(12-72 \mathrm{~h})$. The results are shown for three independent experiments $(n=1-3)$. (d) HeLa cells, reverse transfected with $10 \mathrm{nM}$ of control or GDF15 small interfering RNA (siRNA), were exposed to tunicamycin (10 $\mu \mathrm{M}$ for $20 \mathrm{~h}$ ) alone, or in combination with GRT10 $(0.1 \mu \mathrm{M})$, and the extent of cell death was assessed by PS externalization $(n=3)$. Statistical analysis was conducted by a paired $t$-test ${ }^{* \star \star} P<0.001$, NS, not significant, if $\left.P>0.05\right)$. Immunoblot analysis confirmed the knockdown efficiency of the GDF15 siRNA and the effects on apoptosis, as assessed by cleavage of PARP. (e) Genetic inhibition of maverick (mav), the Drosophila ortholog of GDF15, by RNA interference significantly reverses photoreceptor loss in day $7 \mathrm{HD}$ flies $(n=11-14)$. Statistical analysis was conducted by analysis of variance (ANOVA) with Newman-Keuls post hoc tests ( ${ }^{* \star *} P<0.001$, NS, not significant, if $P>0.05$ ). (f) Newly emerged fruit flies, expressing mutant HTT, following control or mav RNA interference (RNAi), were exposed to DMSO or GRT10 $(10 \mu \mathrm{M}, n=11)$ for 7 days and the number of rhabdomeres per ommatidium was scored by pseudopupil analysis. Statistical analysis was conducted by ANOVA with Newman-Keuls post hoc tests ${ }^{* \star \star} P<0.001$, NS, not significant, if $P>0.05$ ) 
induced apoptosis and provide further mechanistic insight to the regulation of GDF15.

GDF15 (also known as NAG1 or MIC1) is a member of the TGF- $\beta$ superfamily of proteins and has been implicated in

various pathologies including inflammation, cancer, cardiovascular diseases and obesity. ${ }^{65}$ In the central and peripheral nervous systems, GDF15 is widely expressed and is particularly induced in neuronal lesions and cerebral

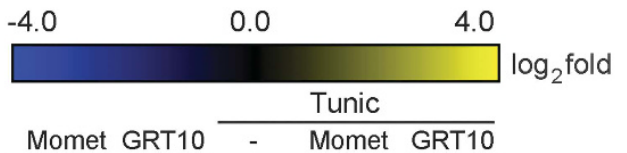

(n) 123123123123123
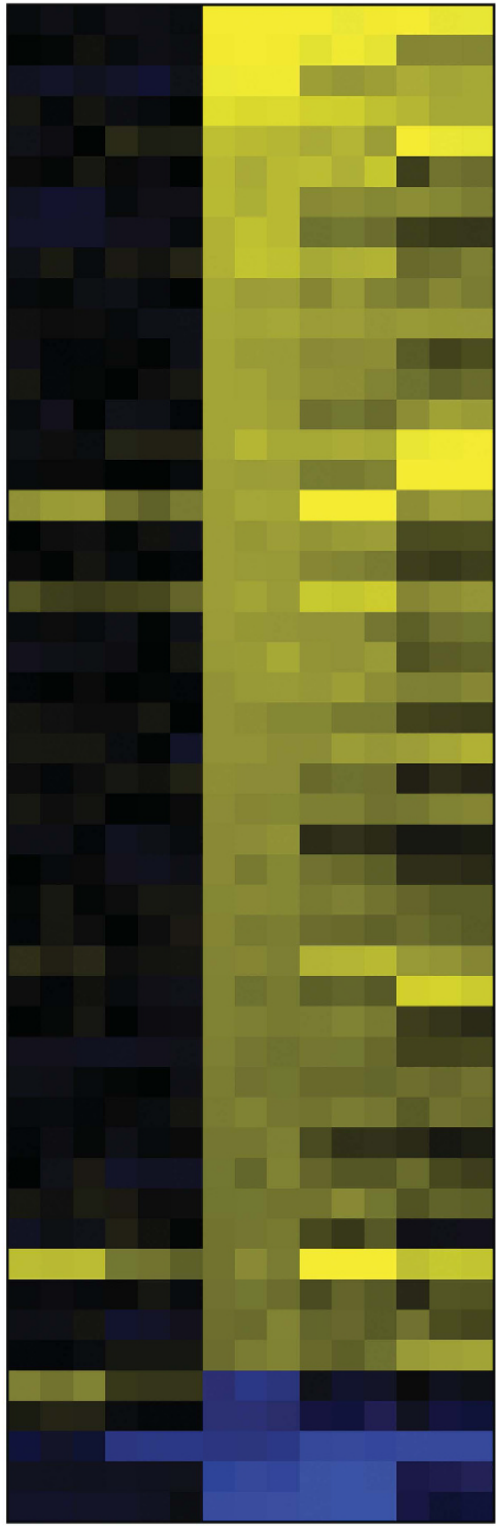

DDIT3 / CHOP HERPUD1 GDF15

TRIB3

FAM129A

LOC400750

PPP1R15A

ATF3

DNAJB9 / ERDJ4

$\angle A R P 6$

HSPA5 / BiP

SESN2

SDF2L1

INHBE

C1ORF24

BEX2

ERRFI1

CHAC1

ETV5

GADD45A

ADM2

CTH

PCK2

FICD

HYOU1

PHLDA1

PDIA4

IL6

CDK2AP2

TMEM5OB

CDH15

TXNIP

CRELD1

GPT2

STC2

ASNS

PSPH

RGS16

$P 8$

$X B P 1$

FGF2

TSC22D3

SYVN1

NUPR1

TRA1P2

EDN2

LFNG

FGFBP1

HSPA1B

HSPA1A

b

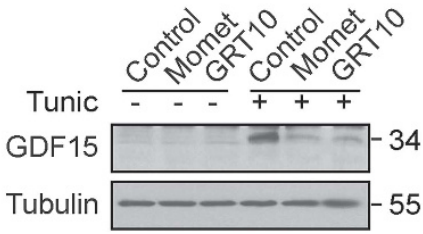

c

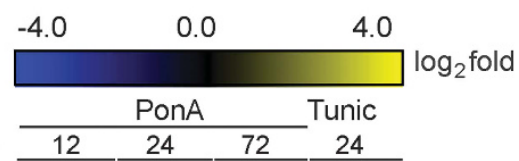

(n) 123123123123
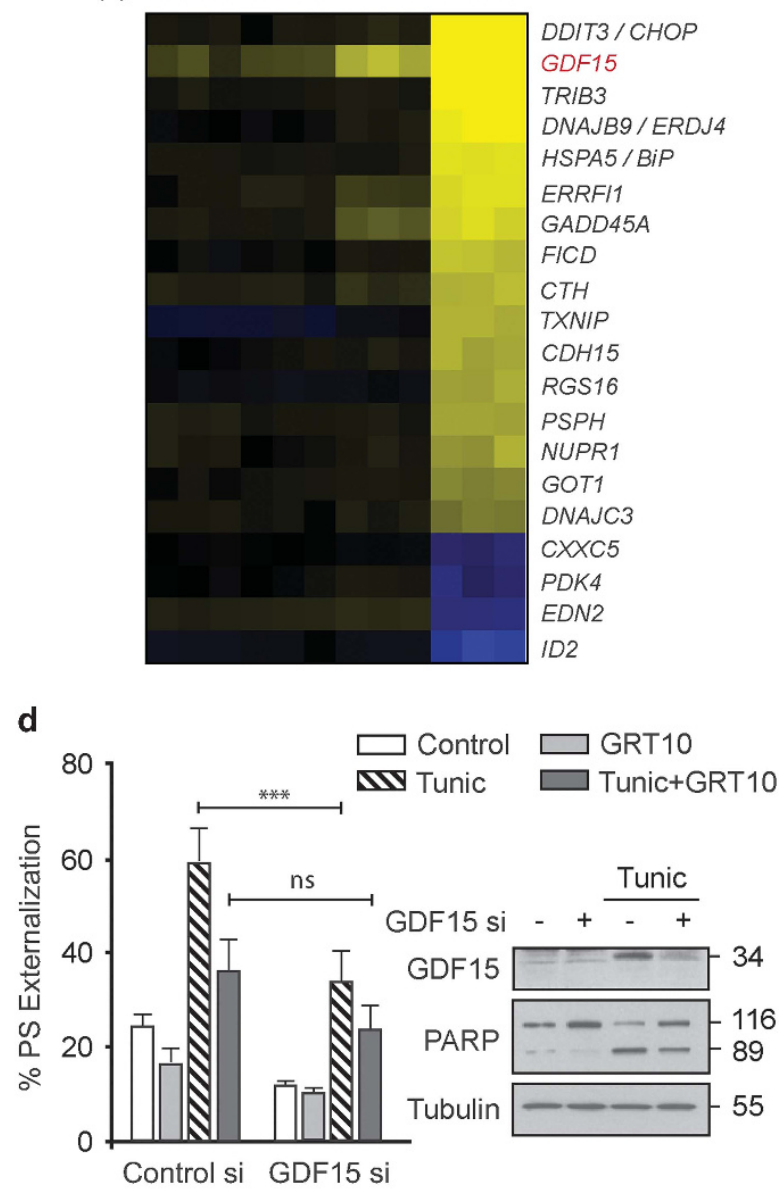

e
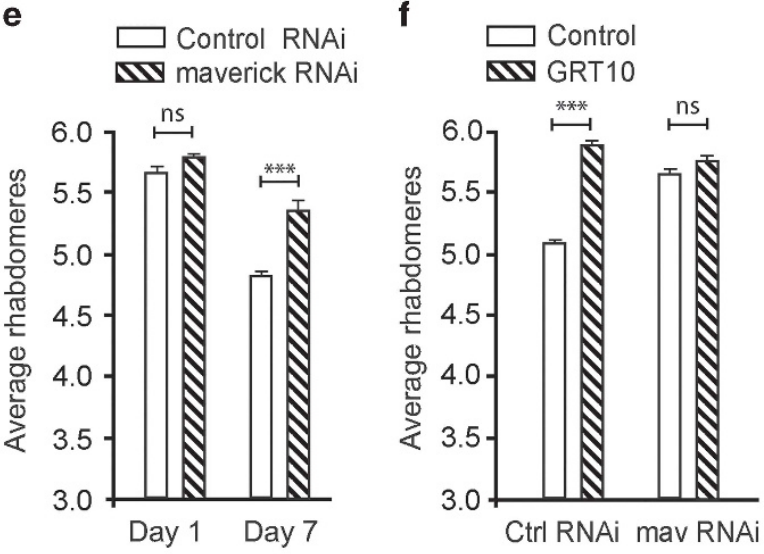


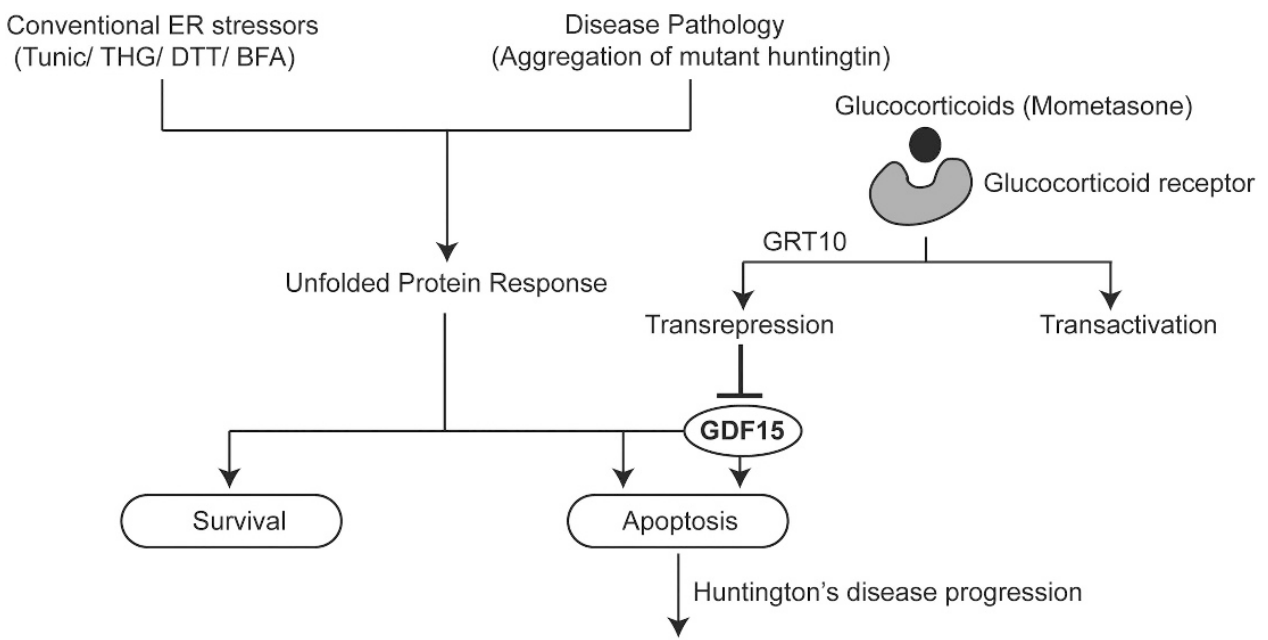

Rhabdomere loss

Neurodegeneration

Figure 5 The transrepression arm of glucocorticoid signaling antagonizes ER stress-induced upregulation of GDF15 and apoptosis, thereby diminishing mutant HTTmediated neurodegeneration. Schematic representation depicting the induction of the UPR following various stress stimuli, resulting in prosurvival or apoptotic signaling pathways depending on the extent of stress. Here, we report a novel crosstalk between the glucocorticoid signaling pathway and the apoptotic arm of the UPR. Binding of glucocorticoids to their receptors can elicit transrepression and/or transactivation as part of their signaling cascade. Using a selective modulator of glucocorticoid signaling, GRT10, we confirm that the upregulation of GDF15 is an important event in the apoptotic arm of the UPR. Furthermore, by selective activation of the transrepression arm of glucocorticoid signaling, we demonstrate that downregulation of GDF15 is efficient in antagonizing ER stress-induced apoptosis, both in HeLa cells and also in a fruit fly model of HD. Exposure to glucocorticoids or a genetic inhibition of GDF15 ameliorated the disease pathology and was neuroprotective in adult HD flies and during development

ischemia. ${ }^{66}$ However, the role of GDF15 in disease pathologies associated with CNS lesions is further complicated by the progressive loss of neurons, motor axons and rotarod skills in GDF15-deficient mice, suggesting the importance of GDF15 in neuronal health. ${ }^{67}$ In this study, we observe that GDF15 is upregulated under stress conditions, and normalization of its function via RNA interference or pharmacological inhibition resulted in a marked protection against both ER stressinduced apoptosis and HD-associated neurodegeneration (Figure 4). Thus, typical of several members of the TGF- $\beta$ superfamily, GDF15 performs opposing functions in disease conditions, and hence further studies are required to identify specific molecular functions of this protein. ${ }^{65}$ Nevertheless, our study conclusively demonstrates that the novel crosstalk between GDF15 and the transrepression arm of glucocorticoid signaling could be an important target in the design of drugs to alleviate several neurodegenerative disorders, including HD, Alzheimer's and Parkinson's diseases.

\section{Materials and Methods}

Cell culture. HeLa cells from ATCC (LGC Standards, Middlesex, UK) were cultured in DMEM medium supplemented with $5 \mathrm{mM}$ L-glutamine and $10 \%$ fetal calf serum (FCS) (all from Life Technologies Inc., Paisley, UK). PC12 cells, stably transfected with a ponasterone A-inducible mutant $\mathrm{HTT}$ fragment (103Q) fused with green fluorescent protein (GFP) ${ }^{39}$ (kindly provided by Leslie Thompson, University of California, Irvine, Irvine, CA, USA), were cultured in DMEM supplemented with $10 \%$ horse serum (v/v), 5\% FCS (v/v), $2 \mathrm{mM}$ GlutaMax and $1 \mathrm{mM}$ sodium pyruvate (all from Life Technologies).

Drosophila transgenic lines. Flies were raised on standard maize media, in LD 12:12 at $25^{\circ} \mathrm{C}$. The elavGAL4 [c155] driver and $\mathrm{y}^{1} \mathrm{scV}^{1} ;$ P PTRiP.GL01025\} attP40 were obtained from the Bloomington Stock Center (Bloomington, IN, USA). The $w ;+;$ UAS HTT93Q exon 1 flies were a gift from Larry Marsh and Leslie Thompson (University of California, Irvine, Irvine, CA, USA). ${ }^{34}$
Reagents and antibodies. All steroids (mometasone furoate, dexamethasone, fluticasone propionate, budesonide and deoxycorticosterone acetate) and ER stress agents (tunicamycin, BFA, THG and DTT) were from Tocris Bioscience (Bristol, UK). Guanabenz was kindly provided by Medical Research Council Technology (London, UK). Ponasterone A was from Santa Cruz Biotechnology (Santa Cruz, CA, USA). Antibodies against glucocorticoid receptor, phospho- and total elF2 $\alpha$ from Cell Signaling Technology Inc. (Danvers, MA, USA), PARP from Alexis Biochemicals (Nottingham, UK), tubulin from Calbiochem (Darmstadt, Germany), GDF15, BiP and CHOP from Abcam (Cambridge, UK) and caspase-3, -7 and -9 (a kind gift from Dr Xiao-Ming Sun, MRC Toxicology Unit, Leicester, UK) were used. All other reagents, unless mentioned otherwise, were from Sigma-Aldrich Co. (St. Louis, MO, USA).

Apoptosis measurements and immunoblotting. Apoptosis was assessed by phosphatidylserine (PS) externalization as described previously. ${ }^{68}$ Western blots were carried out according to standard protocols. Briefly, $30 \mu \mathrm{g}$ of total protein lysate (lysed in a buffer of $20 \mathrm{mM}$ Tris- $\mathrm{HCl}, \mathrm{pH} 7.5,150 \mathrm{mM} \mathrm{NaCl}$, $1 \%$ (v/v) Triton X-100, $1 \mathrm{mM}$ EDTA, $30 \mathrm{mM} \mathrm{NaF}, 1 \mathrm{mM}$ glycerolphosphate, $1 \times$ proteinase inhibitor (Roche, West Sussex, UK) and $1 \mathrm{mM} \mathrm{Na}_{3} \mathrm{VO}_{4}$ ) was denatured in sampling buffer $(50 \mathrm{mM}$ Tris- $\mathrm{HCl}, \mathrm{pH} 6.8,10 \%$ (w/v) glycerol, $2 \%(\mathrm{w} / \mathrm{v})$ SDS, $0.02 \%(\mathrm{w} / \mathrm{v})$ bromophenol blue and $2.5 \%(\mathrm{v} / \mathrm{v}) \beta$-mecaptoethanol) and subjected to SDS-PAGE. Proteins were transferred to nitrocellulose membranes, blocked with $5 \%(\mathrm{w} / \mathrm{v})$ milk in Tris-buffered saline Tween-20 and incubated with various primary antibodies. Washed membranes were incubated with horseradish peroxidase-conjugated secondary antibody and protein bands visualized with ECL reagents (GE Healthcare, Bucks, UK).

RT-PCR and XBP-1 splicing. Total RNA extracted (RNAeasy; Qiagen, Hilden, Germany) from cells was reverse-transcribed (Invitrogen, Carlsbad, CA, USA), and the resulting CDNA was used as a template for PCR amplification using primers $5^{\prime}$-TTACGAGAGAAACTCATGGC- $3^{\prime}$ and 5 '-GGGTCCAAGTTGTCCAGA ATGC-3' to generate the $289 \mathrm{bp}$ amplicon of spliced XBP-1, which was resolved on a $2.5 \%$ agarose $/ 1 \times$ TAE gel and visualized.

siRNA knockdowns. HeLa cells were reverse-transfected with $10 \mathrm{nM}$ siRNA of control, glucocorticoid receptor (s6187) or GDF15 (sc-39798) obtained from Ambion (Carlsbad, CA, USA) or Santa Cruz Biotechnology using Interferin Reagent 
(Polyplus Transfection Inc., New York, NY, USA) according to the manufacturer's protocol and processed $72 \mathrm{~h}$ after transfection.

Compound treatment of Drosophila. Fly food medium was liquefied by gentle heating and mixed thoroughly with appropriate glucocorticoid concentrations. Newly emerged flies were transferred to vials containing food mixed with the glucocorticoid and maintained for 7 days, with the food changed daily to ensure a constant drug supply. For rhabdomere analysis at day 0 , flies were crossed and grown on standard maize medium supplemented with $10 \mu \mathrm{M}$ of either glucocorticoid.

Pseudopupil analysis. Treated flies were anaesthetized with $\mathrm{CO}_{2}$ and the heads removed. The heads were mounted face-up on microscope slides and viewed using a Nikon Optiphot-2 microscope (Nikon UK Ltd, Surrey, UK) at $\times 40$ magnification. Approximately 50 ommatidia were counted from about 12 flies per treatment and averaged to acquire the number of rhabdomeres per ommatidium. Statistical analyses were conducted by ANOVA with Newman-Keuls post hoc tests.

Microarray analysis and statistics. Total RNA extracted from HeLa cells exposed to tunicamycin $(10 \mu \mathrm{M})$ for $20 \mathrm{~h}$, followed by a $4 \mathrm{~h}$ pretreatment with mometasone $(1 \mu \mathrm{M})$ or GRT10 $(0.1 \mu \mathrm{M})$, was used to make biotin-labeled cRNA using the Illumina TotalPrep RNA Amplification Kit (Ambion). The resulting CRNA was hybridized to an Illumina HumanHT-12 BeadChip array (Illumina, San Diego, CA, USA), Cy3 labeled and scanned using an Illumina BeadArray Reader (Illumina). Microarray data normalization and analyses were carried out as before. ${ }^{69}$ For heatmap analysis, the top 50 genes with the highest fold changes $(P \leq 0.003)$, followed by tunicamycin treatment, were compiled. The transcriptional changes of those genes in the treated cells were compared using MultiExperiment Viewer. Microarray analysis on PC12 cells exposed to DMSO or ponasterone A for 12, 24 and $72 \mathrm{~h}$ were carried out as before, but the samples were hybridized to lllumina rat RatRef-12 v1 BeadChip microarrays instead and the microarray data sets for different treatments were compared with the top 20 differentially expressed genes of tunicamycin treatments.

\section{Conflict of Interest}

The authors declare no conflict of interest.

Acknowledgements. We thank the Medical Research Council Toxicology Unit for core support, and the CHDI Foundation Inc. for funding (to FG). We are also grateful to MRCT for guanabenz, Dr. Sun for the caspase- $3,-7$ and -9 antibodies and Drs. Thompson and Marsh for the HTT PC12 cells and fruit flies.

1. Ron $D$, Walter $P$. Signal integration in the endoplasmic reticulum unfolded protein response Nat Rev Mol Cell Biol 2007; 8: 519-529.

2. Walter $P$, Ron $D$. The unfolded protein response: from stress pathway to homeostatic regulation. Science 2011; 334: 1081-1086

3. Schröder M, Kaufman RJ. The mammalian unfolded protein response. Annu Rev Biochem 2005; 74: 739-789.

4. Shore GC, Papa FR, Oakes SA. Signaling cell death from the endoplasmic reticulum stress response. Curr Opin Cell Biol 2011; 23: 143-149.

5. Tabas I, Ron D. Integrating the mechanisms of apoptosis induced by endoplasmic reticulum stress. Nat Cell Biol 2011; 13: 184-190.

6. Wang S, Kaufman RJ. The impact of the unfolded protein response on human disease. J Cell Biol 2012; 197: 857-867.

7. Matus S, Glimcher LH, Hetz C. Protein folding stress in neurodegenerative diseases: a glimpse into the ER. Curr Opin Cell Biol 2011; 23: 239-252.

8. Cornejo VH, Hetz C. The unfolded protein response in Alzheimer's disease. Semin Immunopathol 2013; 35: 277-292.

9. Hetz $C$. The unfolded protein response: controlling cell fate decisions under ER stress and beyond. Nat Rev Mol Cell Biol 2012; 13: 89-102.

10. Boyce M, Bryant KF, Jousse C, Long K, Harding HP, Scheuner D et al. A selective inhibitor of elF2alpha dephosphorylation protects cells from ER stress. Science 2005; 307: 935-939.

11. Tsaytler $P$, Harding HP, Ron D, Bertolotti A. Selective inhibition of a regulatory subunit of protein phosphatase 1 restores proteostasis. Science 2011; 332: 91-94.

12. Okada T, Haze K, Nadanaka S, Yoshida H, Seidah NG, Hirano Y et al. A serine protease inhibitor prevents endoplasmic reticulum stress-induced cleavage but not transport of the membrane-bound transcription factor ATF6. J Biol Chem 2003; 278: 31024-31032.

13. Papandreou I, Denko NC, Olson M, Van Melckebeke H, Lust S, Tam A et al. Identification of an Ire1alpha endonuclease specific inhibitor with cytotoxic activity against human multiple myeloma. Blood 2011; 117: 1311-1314.
14. Mimura N, Fulciniti M, Gorgun G, Tai Y-T, Cirstea D, Santo L et al. Blockade of XBP1 splicing by inhibition of IRE1 $\alpha$ is a promising therapeutic option in multiple myeloma. Blood 2012; 119: $5772-5781$.

15. Barnes PJ. Molecular mechanisms and cellular effects of glucocorticosteroids. Immunol Allergy Clin N Am 2005; 25: 451-468.

16. Gaynon PS, Lustig RH. The use of glucocorticoids in acute lymphoblastic leukemia of childhood. Molecular, cellular, and clinical considerations. J Pediatr Hematol Oncol 1995; 17: $1-12$.

17. Weller M. Glucocorticoid treatment of primary CNS lymphoma. J Neurooncol 1999; 43: 237-239.

18. Gündisch S, Boeckeler E, Behrends U, Amtmann E, Ehrhardt H, Jeremias I. Glucocorticoids augment survival and proliferation of tumor cells. Anticancer Res 2012; 32: 4251-4261.

19. Volden PA, Conzen SD. The influence of glucocorticoid signaling on tumor progression. Brain Behav Immun 2013; 30: S26-S31.

20. Herr I, Büchler MW, Mattern J. Glucocorticoid-mediated apoptosis resistance of solid tumors. Results Probl Cell Differ 2009; 49: 191-218.

21. Vilasco M, Communal L, Mourra N, Courtin A, Forgez P, Gompel A. Glucocorticoid receptor and breast cancer. Breast Cancer Res Treat 2011; 130: 1-10.

22. Strehl C, Buttgereit F. Optimized glucocorticoid therapy: teaching old drugs new tricks. Mol Cell Endocrinol 2013; 380: 32-40.

23. Newton R, Holden NS. Separating transrepression and transactivation: a distressing divorce for the glucocorticoid receptor? Mol Pharmacol 2007; 72: 799-809.

24. Song I-H, Gold R, Straub RH, Burmester G-R, Buttgereit F. New glucocorticoids on the horizon: repress, don't activate!. J Rheumatol 2005; 32: 1199-1207.

25. Rhen T, Cidlowski JA. Antiinflammatory action of glucocorticoids - new mechanisms for old drugs. N Engl J Med 2005; 353: 1711-1723.

26. Schäcke H, Hennekes H, Schottelius A, Jaroch S, Lehmann M, Schmees N et al. SEGRAs: a novel class of anti-inflammatory compounds. Ernst Schering Res Found Workshop 2002; 40: $357-371$

27. Schäcke $H$, Berger $M$, Rehwinkel $H$, Asadullah $K$. Selective glucocorticoid receptor agonists (SEGRAs): novel ligands with an improved therapeutic index. Mol Cell Endocrinol 2007; 275: 109-117.

28. Zhang J-Z, Cavet ME, VanderMeid KR, Salvador-Silva M, López FJ, Ward KW. BOL-303242-X, a novel selective glucocorticoid receptor agonist, with full antiinflammatory properties in human ocular cells. Mol Vis 2009; 15: 2606-2616.

29. Uings IJ, Needham D, Matthews J, Haase M, Austin R, Angell D et al. Discovery of GW870086: a potent anti-inflammatory steroid with a unique pharmacological profile. Br J Pharmacol 2013; 169: 1389-1403.

30. Cavet ME, Harrington KL, Ward KW, Zhang J-Z. Mapracorat, a novel selective glucocorticoid receptor agonist, inhibits hyperosmolar-induced cytokine release and MAPK pathways in human corneal epithelial cells. Mol Vis 2010; 16: 1791-1800.

31. Schäcke H, Zollner TM, Döcke WD, Rehwinkel H, Jaroch S, Skuballa W et al. Characterization of ZK 245186, a novel, selective glucocorticoid receptor agonist for the topical treatment of inflammatory skin diseases. Br J Pharmacol 2009; 158: 1088-1103.

32. Cadepond F, Ulmann A, Baulieu EE. RU486 (mifepristone): mechanisms of action and clinical uses. Annu Rev Med 1997; 48: 129-156.

33. Valotis A, Neukam K, Elert O, Högger P. Human receptor kinetics, tissue binding affinity, and stability of mometasone furoate. J Pharm Sci 2004; 93: 1337-1350.

34. Steffan JS, Bodai L, Pallos J, Poelman M, McCampbell A, Apostol BL et al. Histone deacetylase inhibitors arrest polyglutamine-dependent neurodegeneration in Drosophila. Nature 2001; 413: 739-743.

35. Campesan S, Green EW, Breda C, Sathyasaikumar KV, Muchowski PJ, Schwarcz R et al. The kynurenine pathway modulates neurodegeneration in a Drosophila model of Huntington's disease. Curr Biol 2011; 21: 961-966.

36. Richards P, Didszun C, Campesan S, Simpson A, Horley B, Young KW et al. Dendritic spine loss and neurodegeneration is rescued by Rab11 in models of Huntington's disease. Cell Death Differ 2011; 18: 191-200.

37. Sajjad MU, Green EW, Miller-Fleming L, Hands S, Herrera F, Campesan S et al. DJ-1 modulates aggregation and pathogenesis in models of Huntington's disease. Hum Mol Genet 2013; 23: 755-766

38. Green EW, Giorgini F. Choosing and using Drosophila models to characterize modifiers of Huntington's disease. Biochem Soc Trans 2012; 40: 739-745.

39. Apostol BL, Kazantsev A, Raffioni S, Illes K, Pallos J, Bodai L et al. A cell-based assay for aggregation inhibitors as therapeutics of polyglutamine-repeat disease and validation in Drosophila. Proc Natl Acad Sci USA 2003; 100: 5950-5955.

40. Ross CA, Tabrizi SJ. Huntington's disease: from molecular pathogenesis to clinical treatment. Lancet Neurol 2011; 10: 83-98.

41. Cardoso F, Seppi K, Mair KJ, Wenning GK, Poewe W. Seminar on choreas. Lancet Neurol 2006; 5: 589-602.

42. Lin MT, Beal MF. Mitochondrial dysfunction and oxidative stress in neurodegenerative diseases. Nature 2006; 443: 787-795.

43. Oliveira JMA. Nature and cause of mitochondrial dysfunction in Huntington's disease: focusing on huntingtin and the striatum. J Neurochem 2010; 114: 1-12.

44. Hetz C, Glimcher LH. Protein homeostasis networks in physiology and disease. Curr Opin Cell Biol 2011; 23: 123-125.

45. Adam OR, Jankovic J. Symptomatic treatment of Huntington disease. Neurotherapeutics 2008; 5: 181-197. 
46. Gow A, Wrabetz L. CHOP and the endoplasmic reticulum stress response in myelinating glia. Curr Opin Neurobiol 2009; 19: 505-510.

47. Hetz C, Thielen P, Matus S, Nassif M, Court F, Kiffin R et al. XBP-1 deficiency in the nervous system protects against amyotrophic lateral sclerosis by increasing autophagy. Genes Dev 2009; 23: 2294-2306.

48. Kouroku Y, Fujita E, Jimbo A, Kikuchi T, Yamagata T, Momoi MY et al. Polyglutamine aggregates stimulate ER stress signals and caspase-12 activation. Hum Mol Genet 2002; 11: $1505-1515$.

49. Nishitoh H, Matsuzawa A, Tobiume K, Saegusa K, Takeda K, Inoue K et al. ASK1 is essential for endoplasmic reticulum stress-induced neuronal cell death triggered by expanded polyglutamine repeats. Genes Dev 2002; 16: 1345-1355.

50. Thomas M, Yu Z, Dadgar N, Varambally S, Yu J, Chinnaiyan AM et al. The unfolded protein response modulates toxicity of the expanded glutamine androgen receptor. J Biol Chem 2005; 280: 21264-21271.

51. Duennwald ML, Lindquist S. Impaired ERAD and ER stress are early and specific events in polyglutamine toxicity. Genes Dev 2008; 22: 3308-3319.

52. Cho KJ, Lee BI, Cheon SY, Kim HW, Kim HJ, Kim GW. Inhibition of apoptosis signal-regulating kinase 1 reduces endoplasmic reticulum stress and nuclear huntingtin fragments in a mouse model of Huntington disease. Neuroscience 2009; 163: 1128-1134.

53. Lee H, Noh J-Y, Oh Y, Kim Y, Chang J-W, Chung C-W et al. IRE1 plays an essential role in ER stress-mediated aggregation of mutant huntingtin via the inhibition of autophagy flux. Hum Mol Genet 2012; 21: 101-114.

54. Reijonen S, Putkonen N, Nørremølle A, Lindholm D, Korhonen L. Inhibition of endoplasmic reticulum stress counteracts neuronal cell death and protein aggregation caused by N-terminal mutant huntingtin proteins. Exp Cell Res 2008; 314: 950-960.

55. Jiang Y, Lv H, Liao M, Xu X, Huang S, Tan H et al. GRP78 counteracts cell death and protein aggregation caused by mutant huntingtin proteins. Neurosci Lett 2012; 516: 182-187.

56. Noh J-Y, Lee H, Song S, Kim NS, Im W, Kim M et al. SCAMP5 links endoplasmic reticulum stress to the accumulation of expanded polyglutamine protein aggregates via endocytosis inhibition. J Biol Chem 2009; 284: 11318-11325.

57. Carnemolla A, Fossale E, Agostoni E, Michelazzi S, Calligaris R, De Maso L et al. Rrs1 is involved in endoplasmic reticulum stress response in Huntington disease. J Biol Chem 2009; 284: 18167-18173.
58. Vidal RL, Figueroa A, Court FA, Thielen P, Molina C, Wirth $C$ et al. Targeting the UPR transcription factor XBP1 protects against Huntington's disease through the regulation of FoxO1 and autophagy. Hum Mol Genet 2012; 21: 2245-2262.

59. Zuleta A, Vidal RL, Armentano D, Parsons G, Hetz C. AAV-mediated delivery of the transcription factor XBP1s into the striatum reduces mutant Huntingtin aggregation in a mouse model of Huntington's disease. Biochem Biophys Res Commun 2012; 420 558-563.

60. Rodriguez DA, Zamorano S, Lisbona F, Rojas-Rivera D, Urra H, Cubillos-Ruiz JR et al. $\mathrm{BH} 3-$ only proteins are part of a regulatory network that control the sustained signaling of the unfolded protein response sensor IRE1. EMBO J 2012; 31: 2322-2335.

61. Aziz MH, Shen H, Maki CG. Glucocorticoid receptor activation inhibits p53-induced apoptosis of MCF10Amyc cells via induction of protein kinase C. J Biol Chem 2012; 287: 29825-29836.

62. Das I, Png CW, Oancea I, Hasnain SZ, Lourie R, Proctor M et al. Glucocorticoids alleviate intestinal ER stress by enhancing protein folding and degradation of misfolded proteins. J Exp Med 2013; 210: 1201-1216.

63. Maheshwari M, Bhutani S, Das A, Mukherjee R, Sharma A, Kino Y et al. Dexamethasone induces heat shock response and slows down disease progression in mouse and fly models of Huntington's disease. Hum Mol Genet 2014; 23: 2737-2751.

64. Engel KB, Yamamoto KR. The glucocorticoid receptor and the coregulator Brm selectively modulate each other's occupancy and activity in a gene-specific manner. Mol Cell Biol 2011; 31: 3267-3276.

65. Unsicker K, Spittau B, Krieglstein K. The multiple facets of the TGF- $\beta$ family cytokine growth/ differentiation factor-15/macrophage inhibitory cytokine-1. Cytokine Growth Factor Rev 2013; 24: 373-384.

66. Schindowski K, Bohlen und Halbach von O, Strelau J, Ridder DA, Herrmann O, Schober A et al. Regulation of GDF-15, a distant TGF- $\beta$ superfamily member, in a mouse model of cerebral ischemia. Cell Tissue Res 2011; 343: 399-409.

67. Strelau J, Strzelczyk A, Rusu P, Bendner G, Wiese S, Diella F et al. Progressive postnatal motoneuron loss in mice lacking GDF-15. J Neurosci 2009; 29: 13640-13648.

68. Varadarajan S, Vogler M, Butterworth M, Dinsdale D, Walensky LD, Cohen GM Evaluation and critical assessment of putative MCL-1 inhibitors. Cell Death Differ 2013; 20 : $1475-1484$.

69. Varadarajan S, Bampton ETW, Smalley JL, Tanaka K, Caves RE, Butterworth M et al. A novel cellular stress response characterised by a rapid reorganisation of membranes of the endoplasmic reticulum. Cell Death Differ 2012; 19: 1896-1907. 